\title{
Performance of a parabolic trough solar collector
}

\author{
M J Brooks \\ Department of Mechanical Engineering, Mangosuthu Technikon
}

\author{
I Mills \\ Department of Mechanical Engineering, Mangosuthu Technikon
}

\section{T M Harms}

Department of Mechanical Engineering, University of Stellenbosch

\begin{abstract}
The performance of a South African parabolic trough solar collector (PTSC) module has been characterised using the ASHRAE 93-1986 standard. The collector is designed for component testing and development in a solar energy research programme. Low-temperature testing was performed at Mangosuthu Technikon's STARlab facility using water as the working fluid. Both an evacuated glassshielded receiver and an unshielded receiver were tested, with which peak thermal efficiencies of $53.8 \%$ and $55.2 \%$ were obtained respectively. The glass-shielded element offered superior performance at the maximum test temperature, desensitising the receiver to wind and reducing the overall heat loss coefficient by half. The collector time constants for both receivers indicate low thermal inertia and the measured acceptance angles exceed the tracking accuracy of the PTSC, ensuring the collector operates within $2 \%$ of its optimal efficiency at all times. Off-sun thermal loss results and the behaviour of the PTSC under increased angles of incidence are described. A description of the test system components is given.
\end{abstract}

Keywords: parabolic trough collector, time constant, acceptance angle, optical efficiency

\section{Introduction}

Increased deployment of concentrating solar collectors for hot water and process heat supply suggests growing acceptance of the technology and a maturing attitude towards this 'green' source of energy. A notable recent example is Solargenix's synthesis of collector modules with architectural elements to cre- ate a commercial, dual-function factory roof and solar heat source (Cleveland, 2005). The concentrating modules produce $176 \mathrm{~kW}$ of energy at peak efficiency of $56 \%$ for space-cooling, heating and domestic hot water. Other examples include the installation of a $200 \mathrm{~kW}$ parabolic trough field at a US Federal prison in Phoenix, which supplies hot water for inmates' laundry and ablution requirements and similar systems at U.S. Army facilities in Texas and Arizona (National Renewable Energy Laboratory, 2004). Given Southern Africa's high solar radiation levels, potential for deployment of concentrating collector fields is good, however, local research efforts have lagged. This prevents the development of low-cost, indigenous PTSC components.

The primary aim of this study was to establish baseline performance of a PTSC research module, built at Mangosuthu Technikon and tested at the institution's STARlab facility. Results will be used in an ongoing solar research programme to quantify improvements to concentrating collector components, tracking methodologies, operating techniques and the test facility's data acquisition system. Secondly, the study was intended to demonstrate capacity in the field of collector testing through the use of the rigorous ASHRAE 93-1986 (RA 91) standard (ASHRAE, 1991).

\section{PTSC test system}

The PTSC system is operated as a research testbed. Unlike a commercial trough module, the reflective segments of the collector can be easily removed to test alternative materials, as can the receiver. The trough rotates about a North-South axis and is driven by an AC motor. The tracking system comprises a variable speed drive (VSD) and PLC, which sends commands to the motor. A shaft- 
mounted rotary encoder provides angular feedback information (Naidoo, 2005). This choice of components allows different tracking methodologies to be tested via software changes.

The fluid driver is a $960 \mathrm{rev} / \mathrm{min}$ positive displacement pump with flange-mounted $0.75 \mathrm{~kW}$ motor and a high-temperature stator. Pump speed is controlled by a VSD to provide variable flow rate via a manual control in the STARlab control room. High- and low-temperature tanks supply water across a range of temperatures for testing purposes. Thermocouples provide temperature data at ten critical points in the PTSC fluid loop, while Eppley radiometers provide solar irradiance data for thermal efficiency calculations.

The test system is designed for single-person operation. Custom-written LabVIEW software displays and logs test data from the thermocouples and STARlab radiometers. At one-second intervals the software executes the PSA Algorithm for locating the solar vector (Blanco-Muriel et al., 2001) and updates solar time plus key solar angles (declination, azimuth, zenith, trough tracking angle and the angle of incidence). Additionally, real-time thermal efficiency values are generated from the raw data and displayed graphically, helping the operator to stabilise the system before testing. The information available to the test operator, updated each second, includes:

- PSA solar position data

- ASHRAE 93 thermal efficiency

- Instantaneous thermal efficiency

- Collector time constant quotient

- Thermocouple data

- Irradiance data from a Precision Spectral Pyranometer and Normal Incidence Pyrheliometer

- Receiver fluid temperature, density, viscosity, specific heat and thermal conductivity

- Theoretical Reynolds, Prandtl and Nusselt numbers, fluid mass flow rate, friction factor and convective heat transfer coefficient

The operator selects the time-interval at which data is sampled and each batch of values written to file is date- and time-stamped with local clock time as well as solar time. Data files are easily processed

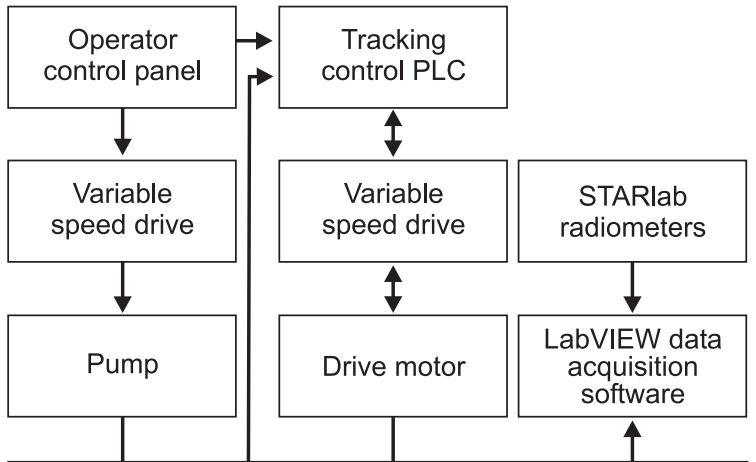

Parabolic trough collector module, incorporating fluid loop and shaft-mounted rotary encoder

Figure 1: Information flow between components of the PTSC test system

in a spreadsheet package after testing. A block diagram of the test system and flow of information between components is given in Figure 1.

Baseline performance was established for a trough module $5 \mathrm{~m}$ long with an aperture width of $1.5 \mathrm{~m}$ (see Figure 2). Rim angle is $82.2^{\circ}$, concentration ratio is 16.7 and the reflective surface consists of stainless steel sheets coated with an $85 \%$ reflective aluminised acrylic film (Brooks, 2005).

\section{Results}

\section{Collector time constant}

The time constant test determines heat capacity or thermal inertia of the receiver and is conducted first to establish the minimum duration of subsequent efficiency tests. It can be determined using either a step input of solar energy when the collector is defocused (heating), or a withdrawal of solar energy while focused (cooling) (Kalogirou, 1996). Time constant is a function of fluid temperature increase or decay, and equals the time required for the quotient $\left(\mathrm{t}_{\mathrm{f}, \mathrm{o}, \mathrm{T}}-\mathrm{t}_{\mathrm{f}, \mathrm{i}}\right) /\left(\mathrm{t}_{\mathrm{f}, \mathrm{o} \text {,initial }}-\mathrm{t}_{\mathrm{f}, \mathrm{i}}\right)$ to change from 0 to 0.632 (heating) or from 1 to 0.368 (cooling). Results for the unshielded receiver are shown in Figures 3 and 4 . For interest, tests were run using a range of flow rates. At the specified test flow rate of $300 \mathrm{~L} / \mathrm{h}$ the cooling and heating time constants were $30.5 \mathrm{~s}$ and $27.7 \mathrm{~s}$ respectively.

Results for the evacuated, glass-shielded receiver are shown in Figures 5 and 6 . At $300 \mathrm{~L} / \mathrm{h}$ the time

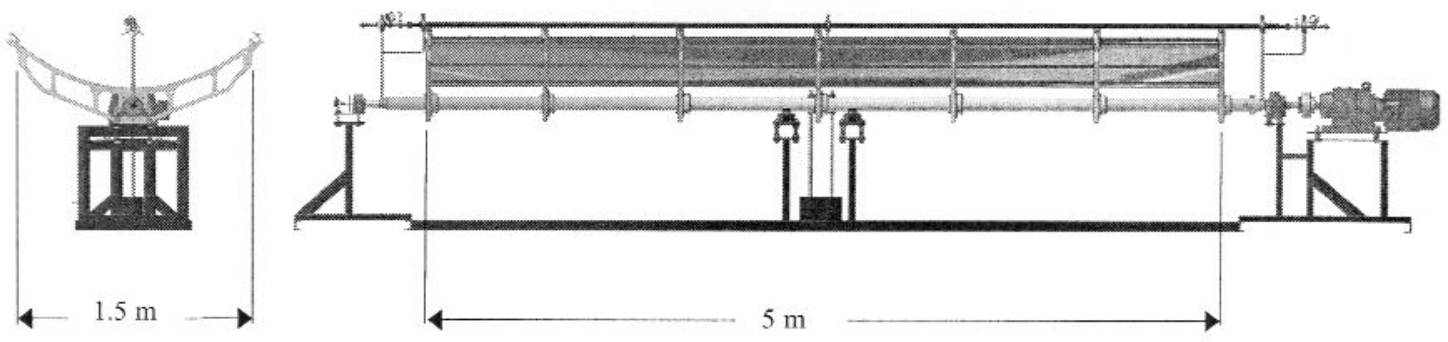

Figure 2: Parabolic trough solar collector 


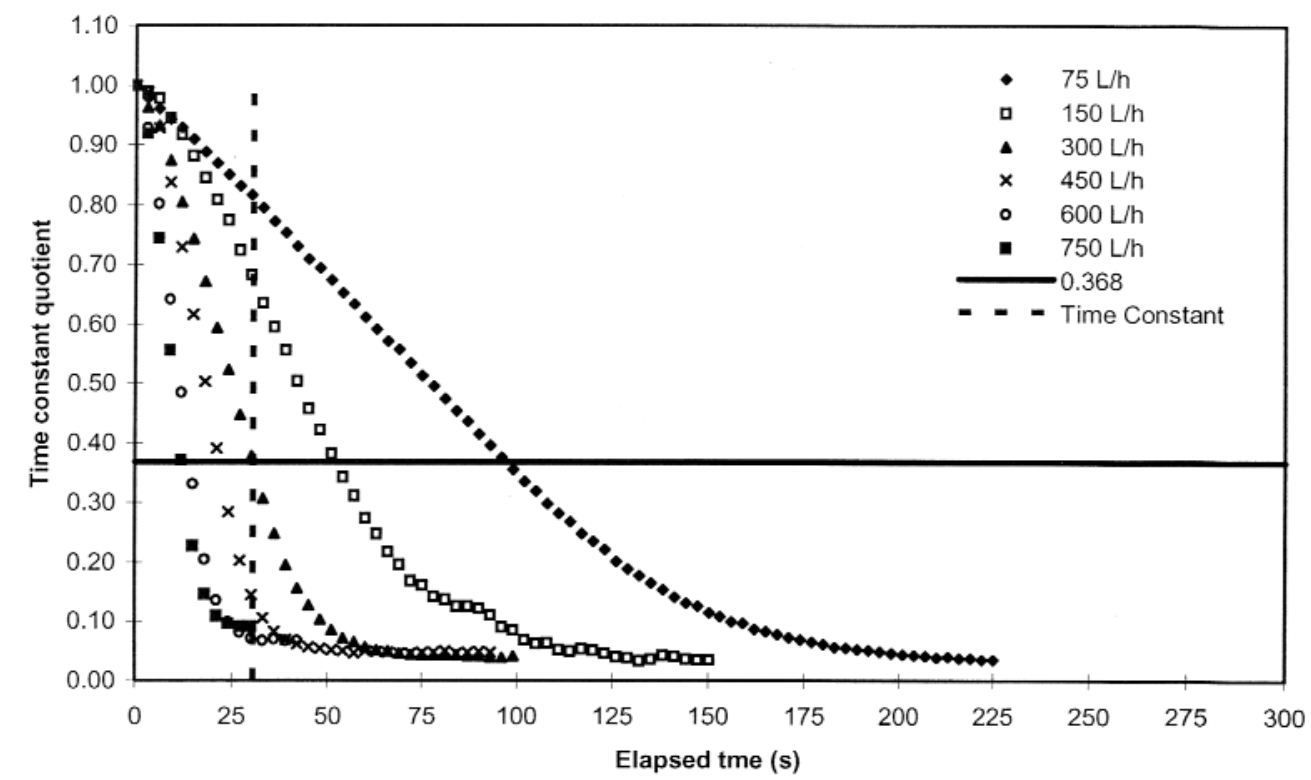

Figure 3: Time constant quotient for unshielded receiver (cooling test)

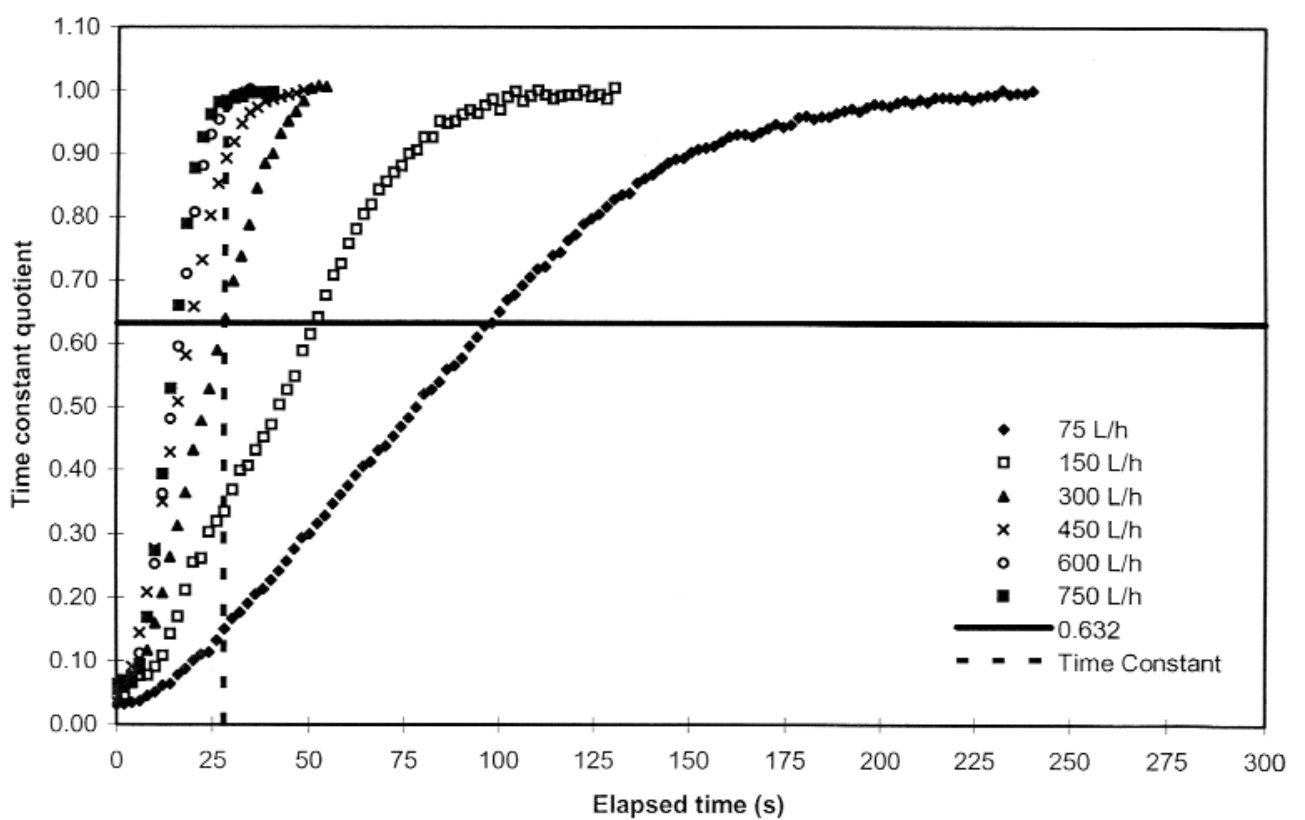

Figure 4: Time constant quotient for unshielded receiver (heating test)

constants were $28.6 \mathrm{~s}$ and $26.4 \mathrm{~s}$. Since the ASHRAE 93 standard stipulates that efficiency tests be run for a period equal to one time constant or 5 min, whichever is larger, the duration of all subsequent tests was set at 5 min.

Time-constant results for the glass-shielded and unshielded receivers were similar with the only significant difference occurring at the lower flow rates of $75 \mathrm{~L} / \mathrm{h}$ and $150 \mathrm{~L} / \mathrm{h}$, where the values for the glass-shielded receiver were higher (see Figure 7).

At the lowest flow rate, the time constants for the shielded receiver were $108.7 \mathrm{~s}$ and $103.2 \mathrm{~s}$ respectively. During cooling at this flow rate, the time constant was $11.4 \%$ higher than the average of the results for the unshielded receiver (97.6 s), while the time constant for the glass receiver under heating was $5.8 \%$ higher. At maximum flow rate the highest time constant was measured for the unshielded receiver during heating, although the results were all close. Results indicate low thermal inertia for the PTSC at the formal test flow rate, while Figure 7 illustrates the exponential behaviour of time constant with flow rate, which was expected given ASHRAE 93's definition of the parameter.

\section{Thermal efficiency}

During efficiency tests, the fluid temperature rose through the receiver $\left(\Delta t_{\mathrm{r}}=\left(\mathrm{t}_{\mathrm{t}, \mathrm{o}}-\mathrm{t}_{\mathrm{f}, \mathrm{i}}\right)\right)$ and the direct normal solar irradiance, GDN, was measured. For a test duration of 5 minutes with data logged at $6 \mathrm{~s}$ intervals, these were processed to give efficiency $\left(\eta_{\mathrm{g}}\right)$ as follows: 


$$
G_{b p}=G_{D N} \cos \theta_{i}
$$

where $G_{b p}$ represents the component of the normal beam irradiance in the plane of the collector aperture and $\theta_{\mathrm{i}}$ is solar angle of incidence.

$$
\begin{aligned}
\eta_{g}= & \frac{\int_{T_{1}}^{T_{2}} m c_{p}\left(t_{f, o}-t_{f, i}\right) d T}{A_{a} \int_{T_{1}}^{T_{2}} G_{b p} d T} \\
= & \frac{\sum_{n=1}^{50} m_{n}\left(c_{p}\right)_{n}\left(t_{f, o}-t_{f, i}\right)_{n} \Delta T_{n}}{A_{a} \sum_{n=1}^{50}\left(G_{b p}\right)_{n} \Delta T_{n}} \\
= & \frac{\sum_{n=1}^{50} m_{n}\left(c_{p}\right)_{n}\left(\Delta t_{r}\right)_{n}}{A_{a} \sum_{n=1}^{50}\left(G_{b p}\right)_{n}}
\end{aligned}
$$

A linear model of $\eta_{\mathrm{g}}$ is imposed on the graph obtained from Equation (2). The performance of the PTSC is then described as:

$$
\eta_{g}=-\left(\frac{A_{r} U_{L} F_{R}}{A_{g}}\right)\left(\frac{\Delta t}{G_{b p}}\right)+\left(\frac{A_{a}}{A_{g}}\right) F_{R} \eta_{o}
$$

The straight line represented by Equation (3) has a gradient of $-\left(\mathrm{A}_{\mathrm{r}} \mathrm{U}_{\mathrm{L}} \mathrm{F}_{\mathrm{R}} / \mathrm{A}_{\mathrm{a}}\right) \mathrm{W} / \mathrm{m}^{2} \mathrm{~K}$ indicating the severity of receiver heat loss, and a y-intercept of $\left(\mathrm{F}_{\mathrm{R}} \eta_{\mathrm{O}}\right)$ giving the peak performance of the collector. The flow factor, $F_{R}$, reduces the useful energy gain from what it would have been had the whole receiver been at the inlet fluid temperature, to the actual heat gain (Duffie and Beckman, 1991). In practice, Equation (3) requires that $\Delta \mathrm{t}$ be varied to determine PTSC performance and inlet temperatures should span the normal operating range of the collector. In this study only low-temperature testing was conducted with receiver inlet temperatures from $20^{\circ} \mathrm{C}$ to $85^{\circ} \mathrm{C}$. Thermal efficiency curves for both receivers are shown in Figure 8.

Twenty tests were conducted to generate the thermal efficiency curve for the PTSC with the unshielded receiver. A best fit curve was obtained from regression analysis using the method of least squares, yielding Equation (4).

$$
\eta_{g}=-2.010\left(\frac{\Delta t}{G_{b p}}\right)+0.552
$$

The coefficient of determination $\left(R^{2}\right)$ is 0.934 , indicating a good fit with the data. From Equation (4), $\left(\mathrm{A}_{\mathrm{r}} \mathrm{U}_{\mathrm{L}} \mathrm{F}_{\mathrm{R}} / \mathrm{A}_{\mathrm{a}}\right)=2.01 \mathrm{~W} / \mathrm{m}^{2} \mathrm{~K}$ and $\mathrm{F}_{\mathrm{R}} \eta_{\mathrm{o}}=0.552$. For a geometric concentration ratio $\left(\mathrm{A}_{\mathrm{a}} / \mathrm{A}_{\mathrm{r}}\right)$ of 16.7 the gradient of Equation (4) gives $U_{L} F_{R}=33.57$ $\mathrm{W} / \mathrm{m}^{2} \mathrm{~K}$. The optical efficiency is calculated from material properties and a statistical estimate of the intercept factor, giving $\eta_{\mathrm{o}}=0.601$ at near-normal angles of incidence. This results in a flow factor of 0.919 and an overall heat loss coefficient $\left(\mathrm{U}_{\mathrm{L}}\right)$ of $36.53 \mathrm{~W} / \mathrm{m}^{2} \mathrm{~K}$.

Due to weather delays, the test programme for

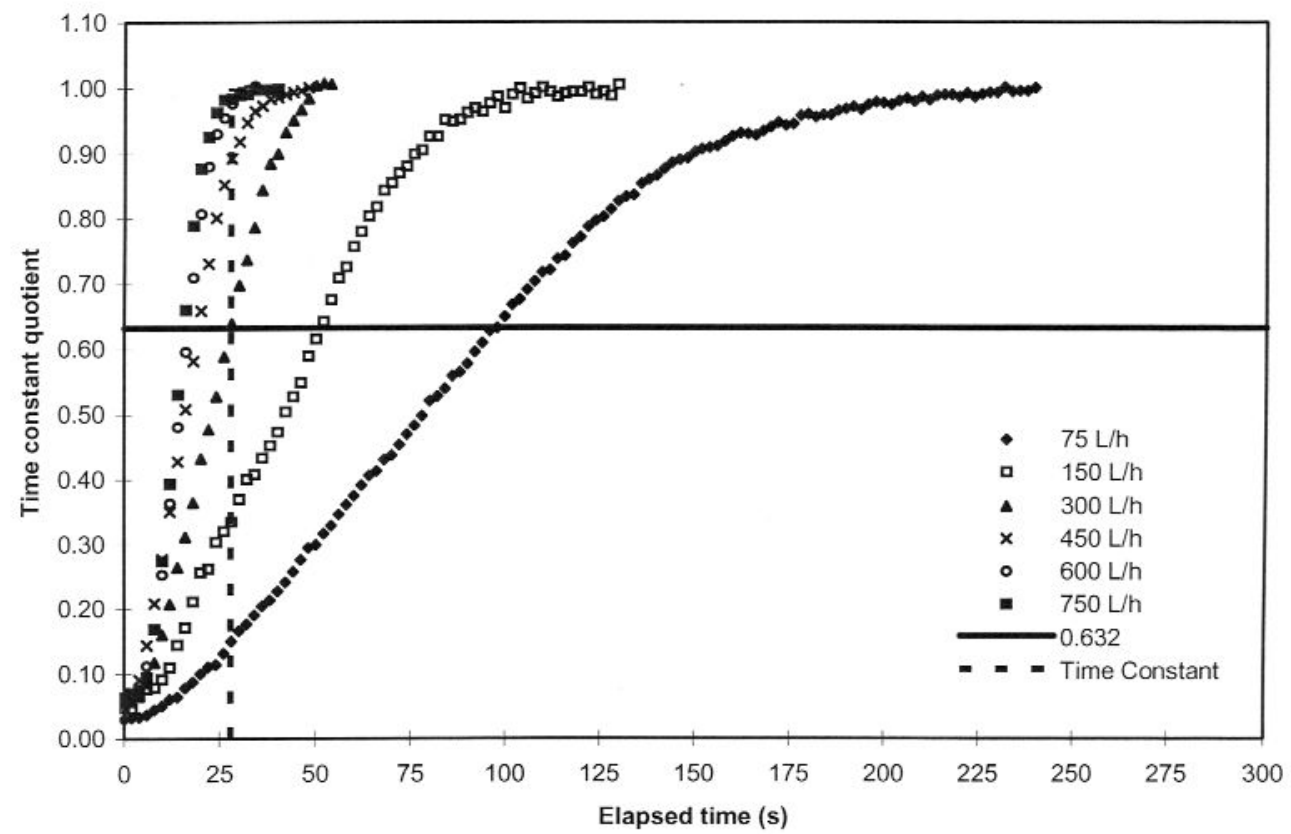

Figure 5: Time constant quotient for glass-shielded receiver (cooling test) 


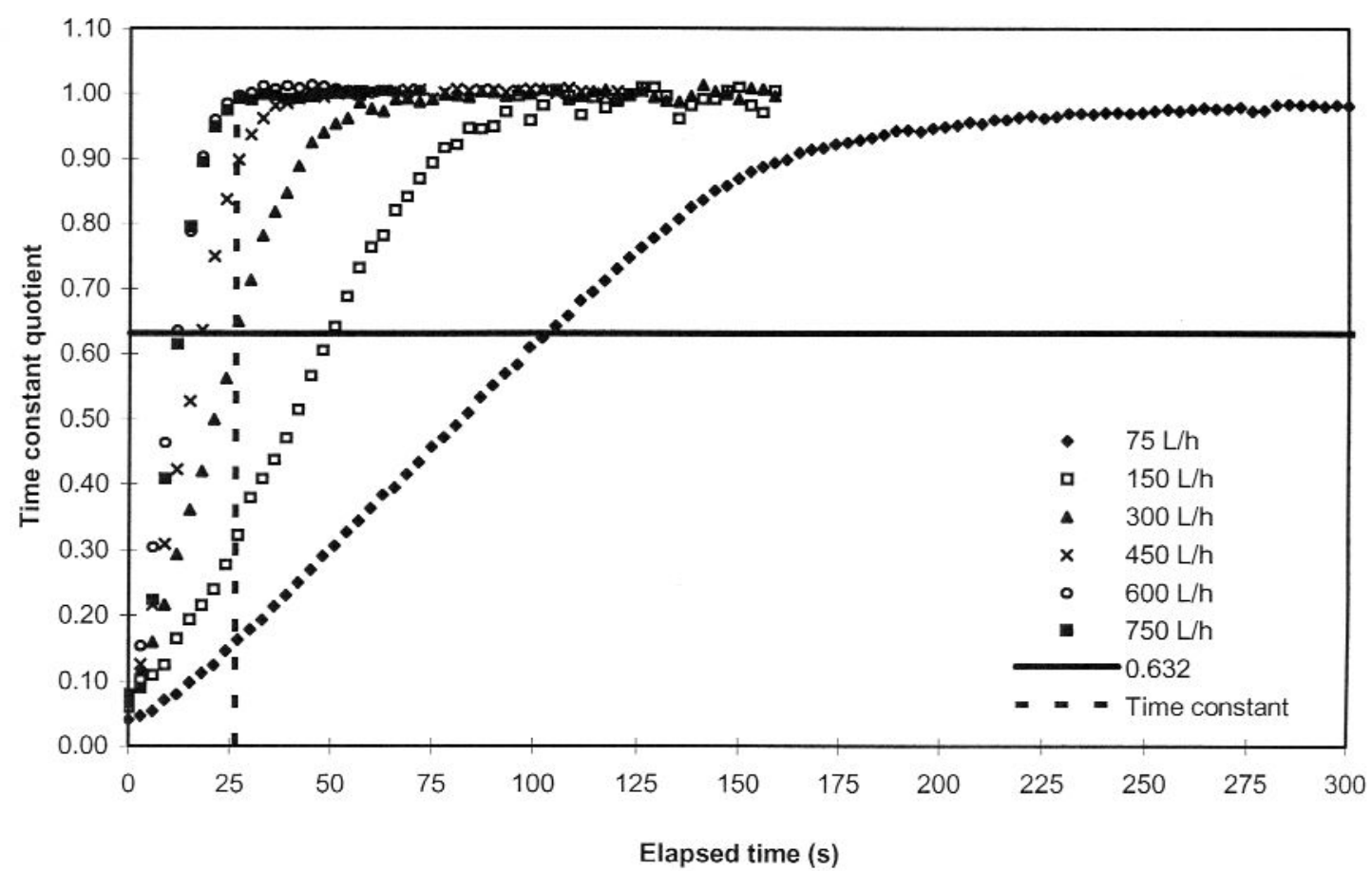

Figure 6: Time constant quotient for glass-shielded receiver (heating test)

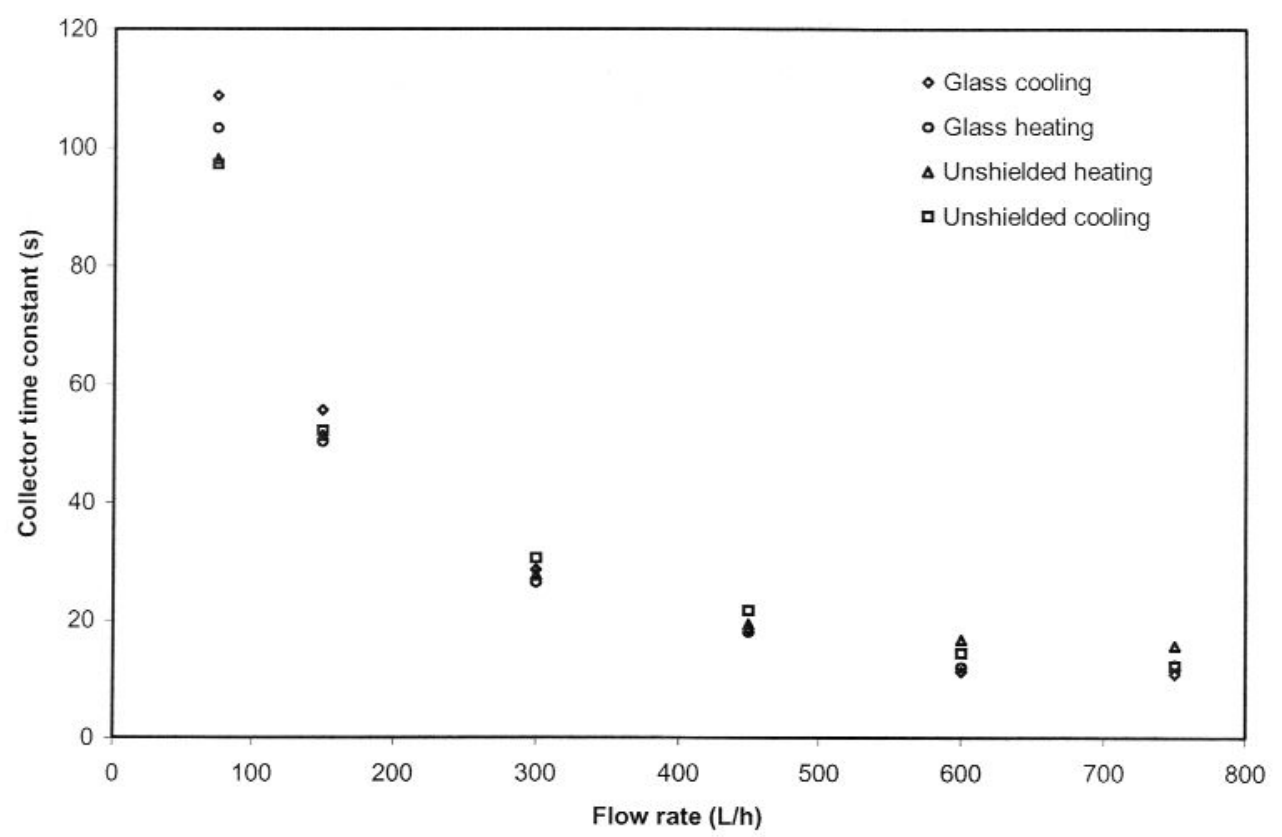

Figure 7: Collector time constant

the glass-shielded receiver was shortened and 10 tests were conducted. A regression analysis yielded the following performance equation:

$\eta_{g}=-1.060\left(\frac{\Delta t}{G_{b p}}\right)+0.538$

For Equation (5), $\mathrm{R}^{2}$ is $0.922,\left(\mathrm{~A}_{\mathrm{r}} \mathrm{U}_{\mathrm{L}} \mathrm{F}_{\mathrm{R}} / \mathrm{A}_{\mathrm{a}}\right)=$ $1.060 \mathrm{~W} / \mathrm{m}^{2} \mathrm{~K}$ and $\mathrm{F}_{\mathrm{R}} \eta_{\mathrm{o}}=0.538$. The gradient gives $\mathrm{U}_{\mathrm{L}} \mathrm{F}_{\mathrm{R}}=17.69 \mathrm{~W} / \mathrm{m}^{2} \mathrm{~K}$. The presence of the glass shield reduces $\eta_{\mathrm{o}}$ from 0.601 to 0.553 at near- normal angles of incidence, giving a flow factor for the shielded receiver of 0.973 and overall heat loss coefficient of $18.18 \mathrm{~W} / \mathrm{m}^{2} \mathrm{~K}$

The point at which the performance curves cross corresponds to a thermal efficiency of $52.2 \%$, with $\left(\Delta t / \mathrm{G}_{\mathrm{bp}}\right)=0.015 \mathrm{~m}^{2} \mathrm{~K} / \mathrm{W}$. For a normal beam irradiance value of $900 \mathrm{~W} / \mathrm{m}^{2}$ this equates to a fluid inlet temperature $13.5^{\circ} \mathrm{C}$ above ambient. For fluid temperatures greater than this, the glass-shielded receiver performs better than the unshielded unit. Below this temperature, heat loss is low and the glass adversely affects performance by reducing 


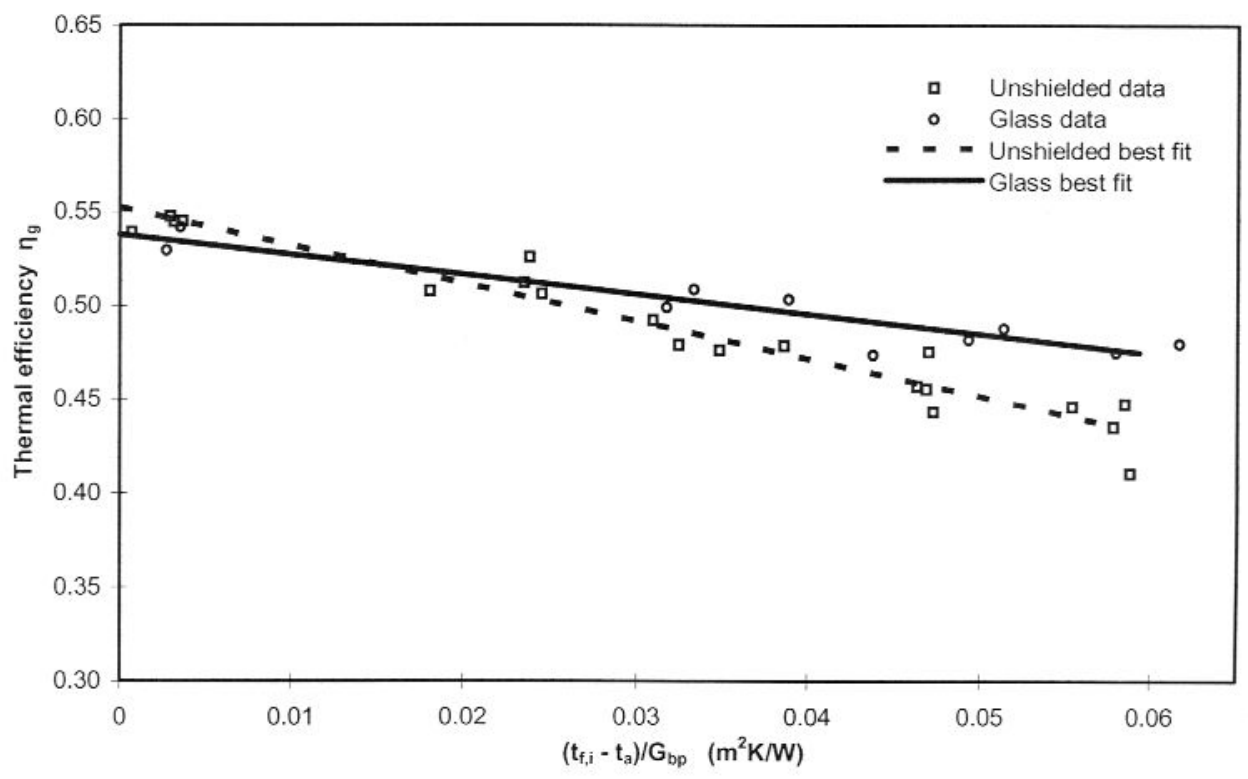

Figure 8: Thermal efficiency

optical efficiency. At higher temperatures performance is dominated by heat loss, which is prevented more effectively by the shielded receiver. In fact, a direct comparison of the thermal efficiency curves is not ideal since they were generated using data obtained at different values of $G_{b p}$ (varying $G_{b p}$ can result in temperature and heat loss changes). However, the efficiency results of Dudley et al. (1995) suggest a very weak dependence on irradiance at low receiver temperatures and a comparison was considered acceptable. Interestingly, the results of Lamprecht (2000) also showed a crossover point in the performance of a trough tested with two receivers (shielded and unshielded) built at the University of Stellenbosch. In this study, the presence of an evacuated glass-shield reduced $\mathrm{U}_{\mathrm{L}}$ by $50.2 \%$ producing a $9.2 \%$ improvement in performance at maximum test temperature. The results show the benefit of installing a glass-shield.

Efficiency results from this study are close to those of other research troughs, for which peak values of $63.8 \%$ (Kalogirou, 1996), 62\% (Ibrahim, 1996) and approximately 45\% (Bakos et al., 1999) are reported in the literature. Most research troughs are smaller than this PTSC however, which is comparable in size to early commercial modules. Overall, the efficiencies are lower than those of commercial troughs that seek outright performance and not flexibility with respect to component exchange. The IST collector tested by Dudley et al. (1995) has a maximum efficiency between $70.8 \%$ and $76.3 \%$ while the newest Eurotrough collector is approximately $75 \%$ efficient (Geyer et al., 2002). This superior performance results mainly from higher intercept factors, highly reflective mirror surfaces and receivers incorporating ceramic-metal coatings with superior solar absorptance.
The temperature range over which a PTSC's efficiency is tested should correspond to the temperatures expected in service, which for commercial units can range from less than $100^{\circ} \mathrm{C}$ to over $400^{\circ} \mathrm{C}$. For a research collector, the range is dictated by the aims of the programme. In this case, the testing of alternative reflective surfaces, tracking methodologies and data acquisition systems does not require a high-temperature working fluid, although a greater temperature range would have been preferred, and will be implemented for future tests on receiver development.

\section{Collector acceptance angle}

Collector acceptance angle defines the sensitivity of the PTSC to tracking misalignment. The collector is held stationery ahead of the sun and thermal efficiency is monitored as a function of PTSC tracking angle $(\rho \mathrm{T})$. Values for each datum point are divided by the peak efficiency recorded at zero angle of incidence, as measured in the same plane in which tracking angle is measured. This yields a form of incidence angle modifier, which is a function of $\rho_{\mathrm{T}}$, not $\theta_{\mathrm{i}}$. The acceptance angle is the range of incident angles in which the incident angle modifier varies by no more than $\pm 2 \%$ from the normal incident value (see Figure 9).

The acceptance angles for the unshielded and glass-shielded receivers $\left(0.43^{\circ}\right.$ and $0.52^{\circ}$ respectively) were similar. The slight asymmetry of the unshielded data indicates either mislocation of the receiver or the asymmetrical effects of other optical errors, such as reflector misalignment. The larger acceptance angle and symmetrical data for the glass-shielded receiver suggest that refraction of incoming light rays by the glass helps to 'damp out' optical image spread. It is also possible that the 


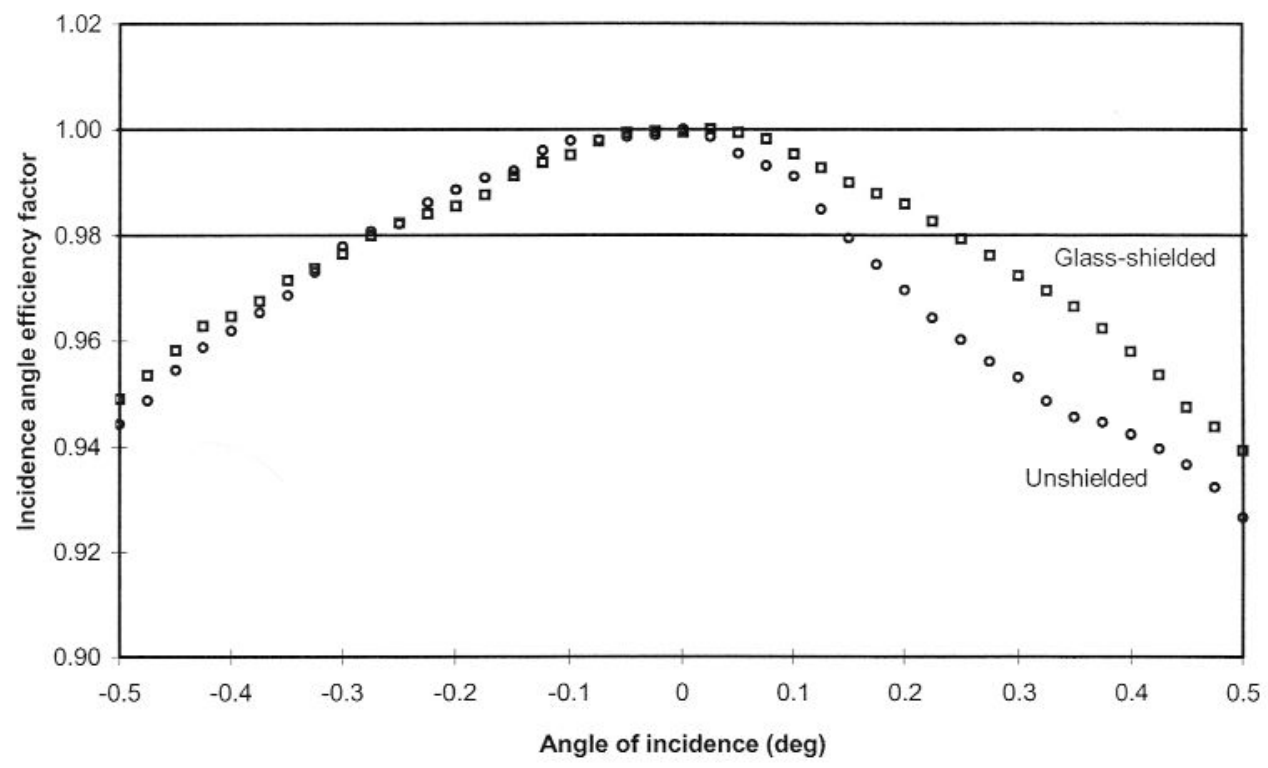

Figure 9: Collector acceptance angle

insulating effect of the glass acts to smooth the thermal efficiency results that make up the data.

Both the ASHRAE 93 standard and Kalogirou (1996) link acceptance angle to tracking accuracy. For this PTSC the tracking accuracy is equal to the angular magnitude of 1 pulse on the feedback rotary encoder, or $0.144^{\circ}$. The collector therefore operates within $2 \%$ of its optimal efficiency since the acceptance angle for both receivers is greater than the angular accuracy of the tracking system.

\section{Incidence angle modifier}

The incidence angle modifier, $\mathrm{K}_{\alpha \tau}\left(\theta_{\mathrm{i}}\right)$, enables the performance of the collector to be predicted for solar angles of incidence other than $0^{\circ}$ (normal). Each test is conducted at a set value of $\theta_{i}$ and $K_{\alpha \tau}$ is calculated using Equation (6).

$$
K_{\alpha \tau}=\frac{\eta_{g}}{\left(A_{a} / A_{g}\right) F_{R}\left[(\tau \alpha)_{e} \rho \gamma\right]_{n}}
$$

The numerator in Equation (6) represents a thermal efficiency value at a specified value of qi, while the denominator represents the peak efficiency of the collector at zero incidence. The ASHRAE 93 standard recommends that qi be increased from zero to a maximum of $60^{\circ}$. A curve-fitting exercise can be applied to the resulting graph to yield an equation for Kat in terms of qi. Kalogirou (1996) presents Kat as a third-order polynomial in qi while Dudley et al. (1995) use a mixed equation in $\cos ($ qi) and (qi)2 to account for their use of GDN in the calculation of efficiency, not Gbp. Results from the tests performed on this PTSC are presented in Figure 10.

Regression analyses provided the following equations for $K_{\alpha \tau}$ as a function of $\theta_{\mathrm{i}}$ :

$$
\begin{aligned}
& \mathrm{K}_{\alpha \tau U}=-2.032 \times 10^{-6}\left(\theta_{\mathrm{i}}\right)^{3}+1.199 \times \\
& 10^{-4}\left(\theta_{\mathrm{i}}\right)^{2}-3.940 \times 10^{-3}\left(\theta_{\mathrm{i}}\right)+1.005 \\
& \mathrm{~K}_{\alpha \tau \mathrm{G}}=9.360 \times 10^{-7}\left(\theta_{\mathrm{i}}\right)^{3}-1.616 \times \\
& 10^{-4}\left(\theta_{\mathrm{i}}\right)^{2}+1.061 \times 10^{-3}\left(\theta_{\mathrm{i}}\right)+1.009
\end{aligned}
$$

The coefficients of determination for Equations (7) and (8) are 0.966 and 0.967. For interest, a cosine plot is included to illustrate the difference between the experimental equations and a much simpler model for the incidence angle modifier, $\mathrm{K}_{\alpha \tau}$.

Up to an incidence angle of approximately $25^{\circ}$ the glass-shielded receiver performed slightly better, but beyond that its performance declined more rapidly and was inferior to that of the unshielded receiver. From Figure 10, the calculated value of $K_{\alpha \tau}$ was 0.75 for the glass-shielded receiver at the maximum tested incidence angle of $53^{\circ}$. This was $9.6 \%$ lower than for the unshielded receiver (0.83). At the same maximum angle of incidence, the simplified cosine model under-predicted $\mathrm{K}_{\alpha \tau}$ by $27.5 \%$ for the unshielded receiver and by $19.8 \%$ for the glassshielded unit.

Two factors are primarily responsible for the decline in performance of a PTSC with increasing $\theta_{i}$ : the geometric reduction in irradiance falling on the aperture as $\theta_{\mathrm{i}}$ increases, called the 'cosine effect' (Stine and Harrigan, 1985), and the change in optical efficiency as light interacts differently with the reflective surface of the collector, the glass shield (if present) and the absorber. Nothing can be done to counter the first effect apart from tilting or rotating the PTSC constantly so as to keep it oriented perpendicular to the sun's rays. In commercial systems this is not possible and the cosine effect must be 


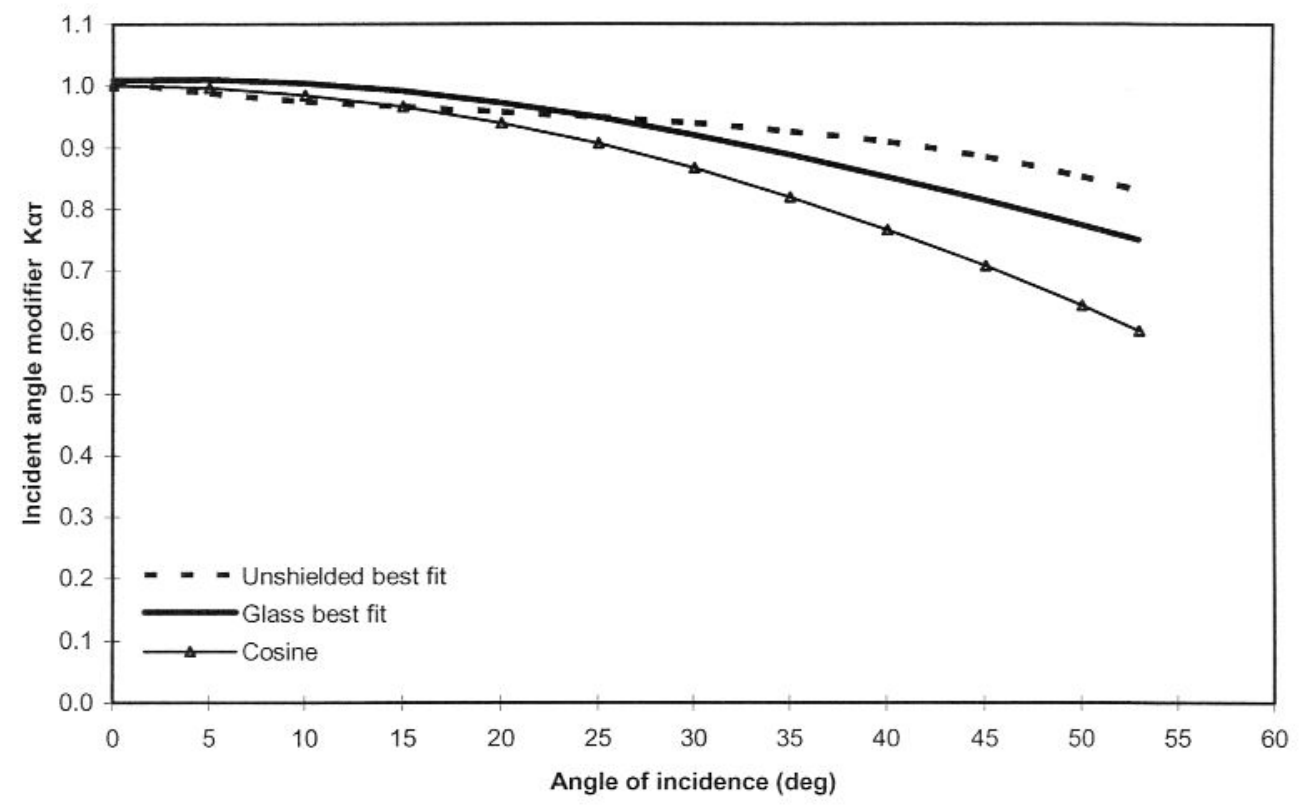

Figure 10: Incidence angle modifier for unshielded and glass-shielded receivers

accounted for when calculating expected energy output from a field of collectors over the course of a year. To calculate the thermal efficiency of a solar collector, only that component of the sun's irradiance normal to the aperture plane should be considered, hence the use of $\mathrm{G}_{\mathrm{bp}}$ in Equation (2) and not $G_{D N}$ (ASHRAE, 1991). Since the cosine effect is accounted for in the calculation of thermal efficien$c y$, it might be expected that trough performance would remain unchanged as $\theta_{\mathrm{i}}$ increased, yet there is a continued reduction in the intercept factor and variation in the mirror surface reflectance, glass transmittance and receiver surface absorptance. Practically, the intercept factor declines because light must travel further from the reflective surface of the trough to the receiver as $\theta_{\mathrm{i}}$ increases, amplifying the effect of optical errors. The material properties change because of the way light interacts with surfaces at different incidence angles. The introduction of the incidence angle modifier $\mathrm{K}_{\alpha \tau}$ allows for the overall effect of these changes to be measured, though it does not account for the cosine effect, which has already been negated in the calculation of $\mathrm{G}_{\mathrm{bp}}$. In the IST test results from Sandia Laboratories, Dudley et al. (1995) use $\mathrm{G}_{\mathrm{DN}}$ in the calculation of efficiency, not $\mathrm{G}_{\mathrm{bp}}$. This reduces thermal efficiency at high angles of incidence since the larger value of $G_{D N}$ appears in the denominator of Equation (2). To accommodate this, their equation for $\mathrm{K}_{\alpha \tau}$ is not a simple polynomial in $\theta_{\mathrm{i}}$ but includes $\mathrm{a} \cos \left(\theta_{\mathrm{i}}\right)$ term.

In this study the PTSC collector structure and reflective surface were identical for both receivers. Assuming the receivers were set up similarly, any change in $\theta_{\mathrm{i}}$ would produce similar changes in intercept factor for both, and any difference in $\mathrm{K}_{\alpha \tau}$ could then be ascribed to the only major difference between the two receivers, namely the glass shield. Since high angles of incidence increase reflection from the surface of a glass cover (Duffie and Beckman, 1991), the crossover point in Figure 10 and subsequent decrease in performance of the glass-shielded receiver, is most likely due to imperfect transmittance of the borosilicate glass.

\section{Thermal loss}

Thermal loss tests are not part of the ASHRAE 93 testing standard, however they are useful in defining steady state heat loss as a function of operating temperature (Dudley et. al, 1995). Water at the maximum test temperature was circulated at 300 $\mathrm{L} / \mathrm{h}$ through the receiver overnight, gradually cooling. By monitoring $\left(t_{f, i}-t_{f, o}\right)$ versus $\left(t_{f, i}-t_{a}\right)$, a measure of the thermal loss in Watts per square meter of receiver area was obtained, this being the 'off-sun' loss $Q_{0}$.

$$
Q_{0}=\frac{m c_{p}\left(t_{f, i}-t_{f, o}\right)}{A_{r}}
$$

Results from the thermal loss tests for both receiver types are given in Figure 11, together with wind data logged during the overnight period.

Following the approach of Dudley et. al (1995) and Stine and Harrigan (1985), the data for off-sun loss were used to generate third order polynomial curves, by regression analysis, describing thermal loss as a function of average receiver fluid temperature above ambient, $\Delta \mathrm{t}_{\text {ave }}$. Equations (10) and (11) give the results for the unshielded and glass-shielded receivers respectively. 


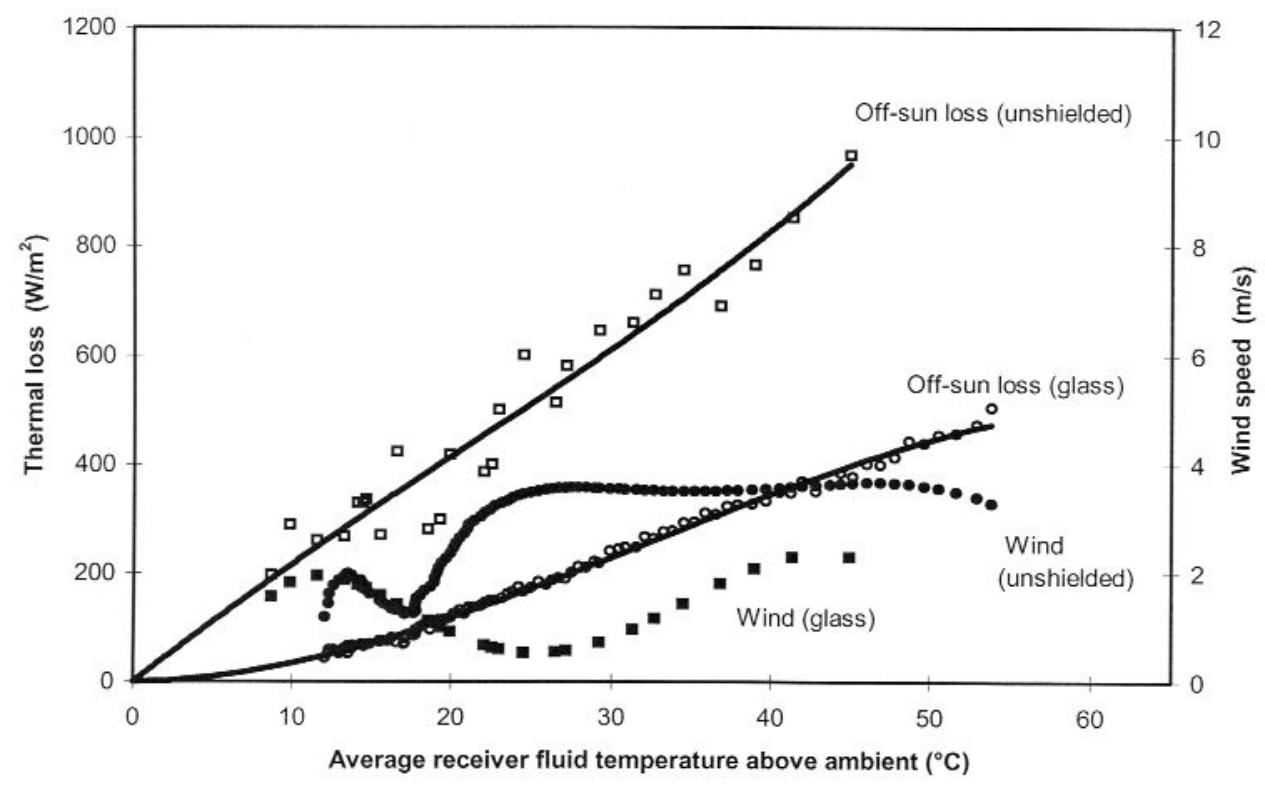

Figure 11: Thermal loss results for both receiver types

Qou $=0.0033\left(\Delta t_{\text {ave }}\right)^{3}-0.1935\left(\Delta t_{\text {ave }}\right)^{2}+$ $23.2746\left(\Delta \mathrm{t}_{\text {ave }}\right) \mathrm{W} / \mathrm{m}^{2}$

$\mathrm{Q}_{0 \mathrm{G}}=-0.0036\left(\Delta \mathrm{t}_{\mathrm{ave}}\right)^{3}+0.3511\left(\Delta \mathrm{t}_{\mathrm{ave}}\right)^{2}+$ $0.3392\left(\Delta t_{\text {ave }}\right) \mathrm{W} / \mathrm{m}^{2}$

For these equations, $\mathrm{R}^{2}$ is 0.936 and 0.995 . For the unshielded receiver, the average value of $\mathrm{G}_{\mathrm{bp}}$, from which the on-sun curve was obtained, was 928.23 $\mathrm{W} / \mathrm{m}^{2}$, while for the glass-shielded receiver the average value was $841.73 \mathrm{~W} / \mathrm{m}^{2}$.

Key results from the thermal loss tests were:

- Characterisation of off-sun loss behaviour for both receivers as a function of $\Delta t_{\text {ave }}$

- Determination of high heat loss sensitivity of the unshielded receiver to variation in wind speed, illustrated in Figure 11 by data scatter.

- Corresponding insensitivity of the glass-shielded receiver.

Care should be exercised in interpreting the results from such tests. In particular:

- Heat loss is affected by wind speed over the receiver, humidity and ambient temperature, which can change between test sessions and even during tests.

- Equations (10) and (11) are not intended to represent an exact model of receiver heat loss, but are an empirical fit of recorded data expressing loss in terms of receiver area. They should not be extrapolated to predict PTSC loss performance outside the range of tested temperatures, since heat loss mechanisms change and the equations do not account for increased radiation loss and other effects.

Clearly, the use of a glass-shield is preferable in reducing heat loss, particularly in high-wind loca- tions. Since wind speed is such an important parameter, it would be advisable to run repeated thermal loss tests to increase the reliability of the data. Results from night tests with similar ambient conditions could then be isolated for comparison. This is suggested for future tests.

\section{Nomenclature}

$\mathrm{A}_{\mathrm{a}} \quad$ Collector aperture area, $\left[\mathrm{m}^{2}\right]$

$\mathrm{A}_{\mathrm{g}} \quad$ Gross collector area, $\left[\mathrm{m}^{2}\right]$

$\mathrm{A}_{\mathrm{r}} \quad$ Receiver area, $\left[\mathrm{m}^{2}\right]$

C Geometric concentration ratio

$\mathrm{c}_{\mathrm{p}} \quad$ Specific heat at constant pressure, $[\mathrm{J} / \mathrm{kgK}]$

$\mathrm{F}_{\mathrm{R}} \quad$ Flow factor

$\mathrm{G}_{\mathrm{bp}} \quad$ Beam in-plane irradiance, $\left[\mathrm{W} / \mathrm{m}^{2}\right]$

GDN Direct normal irradiance, $\left[\mathrm{W} / \mathrm{m}^{2}\right]$

$\mathrm{K}_{\alpha \tau} \quad$ Incidence angle modifier

$\mathrm{m} \quad$ Mass flow rate, $[\mathrm{kg} / \mathrm{s}]$

Qo Off-sun thermal loss per unit area of receiver, $\left[\mathrm{W} / \mathrm{m}^{2}\right]$

$\mathrm{R}^{2} \quad$ Coefficient of determination

T Time, [s]

$t_{a} \quad$ Ambient air temperature, $\left[{ }^{\circ} \mathrm{C}\right]$

$\mathrm{t}_{\mathrm{f}, \mathrm{i}} \quad$ Fluid temperature at inlet to receiver, $\left[{ }^{\circ} \mathrm{C}\right]$

$\mathrm{t}_{\mathrm{f}, \mathrm{o}} \quad$ Fluid temperature at outlet from receiver, $\left[{ }^{\circ} \mathrm{C}\right]$

$\mathrm{t}_{\mathrm{f}, \mathrm{o}}$, initial Initial fluid temperature at receiver outlet, $\left[{ }^{\circ} \mathrm{C}\right]$

$\mathrm{t}_{\mathrm{f}, \mathrm{o}, \mathrm{T}} \quad$ Fluid temperature at receiver outlet at time $\mathrm{T},\left[{ }^{\circ} \mathrm{C}\right]$

$\mathrm{U}_{\mathrm{L}} \quad$ Receiver heat loss coefficient, $\left[\mathrm{W} / \mathrm{m}^{2} \mathrm{~K}\right]$

\section{Greek symbols \\ $\alpha \quad$ Absorptance}


$\mathrm{Y}$ Intercept factor

$\Delta \mathrm{T}$ Time difference or sampling interval, [s]

$\Delta t \quad$ Difference between receiver inlet temperature and ambient, $\left[{ }^{\circ} \mathrm{C}\right]$

$\Delta t_{\text {ave }}$ Difference between average receiver fluid temperature and ambient, $\left[{ }^{\circ} \mathrm{C}\right]$

$\Delta t_{\mathrm{r}} \quad$ Difference between receiver outlet and inlet temperatures, $\left[{ }^{\circ} \mathrm{C}\right]$

$\eta_{\mathrm{g}} \quad$ Thermal efficiency

$\eta_{\mathrm{o}} \quad$ Optical efficiency

$\theta_{\mathrm{i}} \quad$ Angle of incidence of central solar ray with collector aperture, [deg]

$\rho \quad$ Reflectance

$\rho_{\mathrm{T}} \quad$ Collector tracking angle, [deg]

$\tau \quad$ Glass shield transmittance

\section{Acknowledgements}

The authors wish to thank Eskom (TESP), the National Research Foundation (THRIP), USAID, AfricaBlue, Autodesk, UKZN and the Norwegian University of Science and Technology (NTNU) for their support.

\section{References}

ASHRAE (American Society of Heating, Refrigerating and Air-Conditioning Engineers) 1991. Methods of testing to determine the thermal performance of solar collectors. ANSI/ASHRAE 93-1986 (RA 91).

Bakos, G. C., Adamopoulos, D., Soursos, M. and Tsagas, N. F. 1999. Design and construction of a line-focus parabolic trough solar concentrator for electricity generation. In Proceedings of ISES Solar World Congress, Jerusalem.

Blanco-Muriel, M., Alarcón-Padilla D. C., LópezMoratalla T. \& Lara-Coira M. 2001. Computing the solar vector. Solar Energy 70 (5): 431-441.

Brooks, M. J. 2005. Performance of a parabolic trough solar collector, M Sc (Eng) thesis. University of Stellenbosch.

Cleveland, T. 2005. Description and performance of a TRNSYS model of the Solargenix Tracking Power Roof. In Proceedings of ISES Solar World Congress, Orlando.

Dudley, V. E., Evans, L. R. \& Matthews, C. W. 1995. Test results: Industrial Solar Technology parabolic trough solar collector. SAND94-1117. Sandia National Laboratories.

Duffie, J. A. \& Beckman, W. A. 1991. Solar engineering of thermal processes, John Wiley \& Sons, Inc.

Geyer, M., Lüpfert, E., Osuna, R., Esteban, A., Schiel, W., Schweitzer, A., Zarza, E., Nava, P., Langenkamp, J. \& Mandelberg E. 2002. EuroTrough - Parabolic trough collector developed for cost efficient solar power generation. Paper presented at the $11^{\text {th }}$ Int. Symposium on Concentrating Solar Power and Chemical Energy Technologies, Zurich.
Ibrahim, S. M. A. 1996. The forced circulation performance of a sun tracking parabolic concentrator collector. In Proceedings of the World Renewable Energy Congress, Denver.

Kalogirou, S. 1996. Parabolic trough collector system for low temperature steam generation: design and performance characteristics. Applied Energy 55: 1-19

Lamprecht A. J. 2000. Efficiency improvement of parabolic trough solar collector, Mechanical Project 478. University of Stellenbosch.

Naidoo, P. 2005. Intelligent control and tracking of a solar parabolic trough. DTech dissertation. Nelson Mandela Metropolitan University. In preparation.

National Renewable Energy Laboratory. 2004. Heating water with solar energy costs less at the Phoenix Federal Correctional Institution, DOE/GO-1020041914.

Stine, W. B. \& Harrigan, R. W. 1985. Solar energy fundamentals and design with computer applications, John Wiley \& Sons, Inc.

Received 27 October 2005; revised 9 February 2006 